\title{
Abdominal pain in a young girl
}

R Handa, R Chirukpalli, S Agarwal, S Mukhopadhyaya, R Gupta, R Sood, HS Meena, JP Wali

A 14-year-old girl was admitted to our hospital with peri-umbilical pain associated with obstipation and vomiting. Plain erect X-rays of the abdomen revealed multiple air fluid levels. A supine $\mathrm{X}$-ray is shown in the figure.

\author{
All India Institute of \\ Medical Sciences, \\ Ansari Nagar, New \\ Delhi 110029, India \\ Department of \\ Medicine \\ R Handa \\ R Chirukpalli \\ S Agarwal \\ R Sood \\ HS Meena \\ JP Wali \\ Department of \\ Radiology \\ S Mukhopadhyaya \\ R Gupta
}

Accepted 3 May 1995

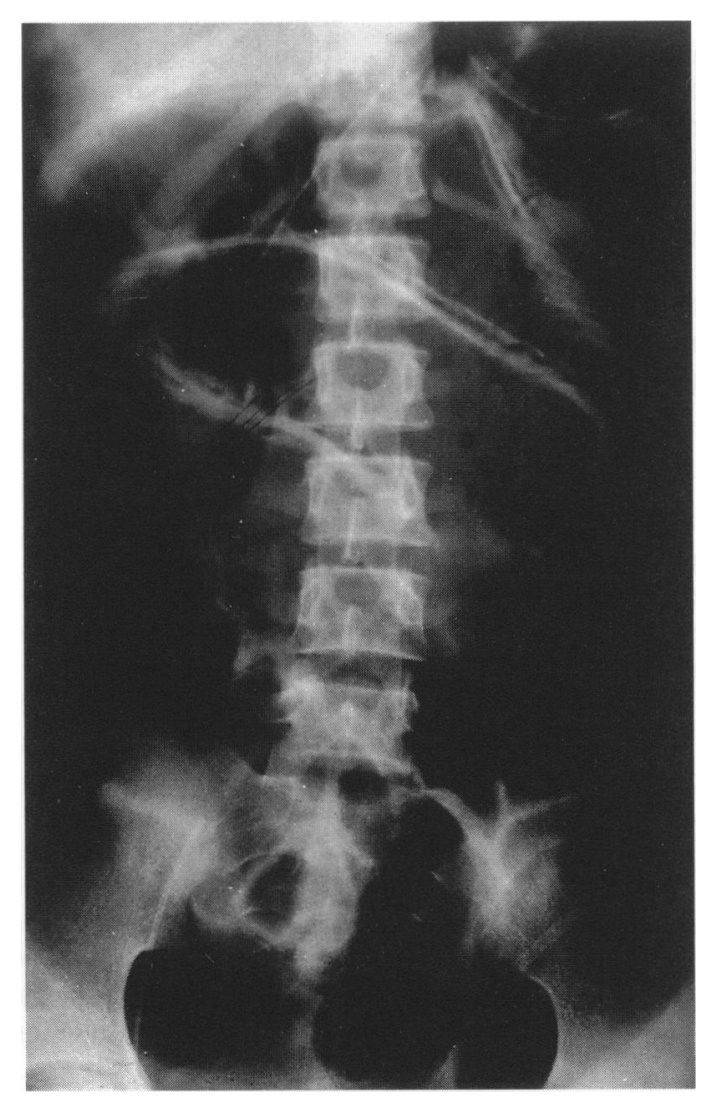

\section{Questions}

1 What does the abdominal X-ray show?

2 What is the diagnosis?

3 What are the aetiologic factors underlying this condition?

4 How is the condition managed?

Figure X-ray of abdomen 


\section{Answers}

\section{QUESTION 1}

The supine abdominal X-ray shows dilated small bowel loops with extensive intramural air in the wall of jejunum. Ryle's tube is seen in situ. No free air is seen under the domes of the diaphragm.

\section{QUESTION 2}

Pneumatosis intestinalis in a patient with small bowel obstruction. This is a condition characterised by the presence of gas in the wall of small or large bowel, either in the form of cysts of less commonly the gas permeates the tissues in a noncystic form ('interstitial emphysema') as in the present case.

\section{QUESTION 3}

The disorders underlying pneumatosis intestinalis differ in the pediatric age group and adults (boxes 1 and 2 ). In about $15 \%$ of cases, the condition is idiopathic. Pneumatosis of the left side of colon is usually idiopathic and that of small bowel and ascending colon is usually secondary. Pneumatosis is not a disease in itself, but is a manifestation of underlying pathology. The significance of this radiological finding varies according to the underlying pathology.

\section{QUESTION 4}

Most often the condition is benign and therapy is dictated by the underlying condition. Highflow oxygen breathing via either a head tent, a nonrebreather mask, or hyperbaric oxygen therapy may help in resolution. The basic

\begin{tabular}{|l|}
\hline $\begin{array}{l}\text { Aetiology of pneumatosis } \\
\text { intestinalis in young children }\end{array}$ \\
\hline - necrotising enterocolitis \\
- imperforate anus \\
- meconium ileus \\
- Hirschsprung's disease \\
bowel ischaemia from intussusception, \\
- idiopathic \\
\hline
\end{tabular}

Box 1

\begin{tabular}{|l|}
\hline $\begin{array}{l}\text { Aetiology of pneumatosis } \\
\text { intestinalis in adults }\end{array}$ \\
\hline - intestinal obstruction \\
- pyloric stenosis due to peptic ulcer \\
- chronic obstructive pulmonary disease \\
- pseudomembranous enterocolitis \\
- inferticulitis \\
- scleroderma \\
- intestinal tuberculosis \\
- enteric anastomosis \\
- mucosal trauma following sigmoidoscopy, \\
- idiopathic or or mucosal biopsy \\
\hline
\end{tabular}

Box 2 principle behind this is that the gas cysts are filled mostly with gases other than oxygen at a pressure above atmospheric. Increasing the concentration of inhaled oxygen results in a higher partial pressure of oxygen and lower partial pressure of nitrogen which results in a pressure gradient with diffusion of cyst gas into the blood. Surgery is indicated only in complications like volvulus and intestinal obstruction.

\section{Discussion}

Pneumatosis intestinalis is a rare condition characterised by the presence of extraluminal gas in the submucosal or subserosal layer of the bowel wall, most often in the form of cysts. In a small number of cases, the gas is not encapsulated and permeates the tissues in a noncystic form. ${ }^{1}$ The disease is three to four times more common in males, the greatest incidence occurring between the ages of 25 and 50 years. The cysts found in infants and children are generally submucosal, whereas those in older children and adults are subserosal. The small bowel is most commonly affected, usually in the distal jejunum or proximal ileal region. More recently, with an increase in the number of sigmoidoscopies and colonoscopies, a change in the overall pattern of disease appears to have occurred with a predilection for gas cysts to affect the left hemicolon, without small intestinal involvement. ${ }^{2}$

\section{PATHOGENESIS}

Mechanical and bacterial theories have been proposed to explain the pathogenesis of pneumatosis intestinalis. ${ }^{3}$ Obstruction results in an increase in peristalsis, intraluminal pressure, and volume of gas. Breaks in mucosal integrity permit entry of intraluminal gas into the bowel wall which is then thought to be transported distally along lymphatic channels by peristalsis. Gas-producing organisms like Clostridium perfringens may penetrate the mucosa or submucosa and have been implicated in the pathogenesis of pneumatosis intestinalis.

\section{PATHOLOGY}

The gas cysts are surrounded by foreign body giant cells and macrophages. The cyst gases are $70-90 \%$ nitrogen, $3-20 \%$ oxygen, carbon dioxide $0-15 \%$, and traces of methane. ${ }^{4}$

\section{CLINICAL PROFILE}

Most cases are asymptomatic and detected incidentally on X-rays of the abdomen. The clinical manifestations of pneumatosis range from non-specific complaints of diarrhoea, constipation, flatulence, and malena to lifethreatening complications of intestinal obstruction, perforation, pneumoperitoneum, and haemorrhage (box 3). Complications occur in approximately $3 \%$ of cases. Symptoms related to any of the concurrent gastrointestinal lesions may dominate the clinical picture. Spontaneous rupture can result in pneumoperitoneum without peritonitis.

The primary radiographic findings are trans- 


\begin{tabular}{|l|}
\hline Complications of pneumatosis \\
intestinalis \\
\hline - volvulus \\
- pneumoperitoneum \\
- intestinal obstruction \\
- intussusception \\
- haemorion pneumoperitoneum \\
- intestinal perforation \\
\hline
\end{tabular}

\section{Box 3}

lucent areas within the contour of normal bowel. Lateral decubitis film may help to establish that the gas is not free within the peritoneal cavity. Barium studies, not necessary for diagnosis, may reveal inconsistent translucent filling defects between the contrast medium and the outer limits of the intestinal wall. Cysts should be differentiated from polyps and tumours. Unlike polyps, cyst size will change with flattening of the base on distortion of the colon. The smooth contour of the cysts helps differentiate them from tumours. Accurate diagnosis is important to prevent colectomies for polyposis and abdominoperineal resections for cancer. The presence of portal venous gas detected on abdominal ultrasound connotes a poor prognosis. $^{5}$

\section{THERAPY}

Pneumatosis intestinalis usually resolves with adequate treatment of the underlying disease.

1 Wertkin MG, Wetchler BB, Waye JD, Brown LK Pneumatosis coli associated with sigmoid volvulus and colonoscopy. Am f Gastroenterol 1976; 65: 209-14.

2 Gillson J, Holt $S$, Sircus W. Pneumatosis coli and sigmoid volvulus: a report of 4 cases. Br $\mathcal{F}$ Surg 1979; 29: 189-95.

3 Galandiuk S, Fazio VM. Pneumatosis cystoides intestinalis a review of the literature. Dis Colon Rectum 1986; 29: 358-63.

\section{Pneumatosis intestinalis}

Extraluminal gas in the submucosa or subserosa of the bowel wall - most often cystic, rarely in free form

Box 4

High-flow oxygen may help resolution. Recurrences have been known to occur after treatment. Surgery is indicated only when complications occur.

\section{Conclusions}

Pneumatosis intestinalis is a rare condition which is most often noted as an incidental finding on X-ray or at laparotomy. The prognosis is governed by the underlying condition. A high index of suspicion is required and pneumoperitoneum in a patient without sign or symptoms of peritonitis should alert the clinician to the possibility of pneumatosis intestinalis. Correct radiographic diagnosis helps avoid unnecessary surgery.

\section{Final diagnosis}

Pneumatosis intestinalis

Keywords: pneumatosis intestinalis, abdominal pain

4 McGregor JK, McKinnon DA Jr. Intestinal interstial emphysema. Gastroenterology 1958; 35: 206-11.

5 Yip CKY, Ng VK, Man DWK, Metreweli C. Sonographic recognition of pneumatosis intestinalis and portal gas in an 11 months old infant. Australas Radiol 1990; 34: 169-71. 